\title{
CLINICAL INDICATORS OF CHILD DEVELOPMENT IN THE CAPITALS OF NINE BRAZILIAN STATES: THE INFLUENCE OF REGIONAL CULTURAL FACTORS
}

\author{
André Laranjeira de Carvalho, Luiz Fernando Ferraz da Silva, Sandra Josefina \\ Ferraz Ellero Grisi, Ana Maria de Ulhôa Escobar
}

Carvalho AL, Silva LFF, Grisi SJFE, Escobar AMU. Clinical indicators of child development in the capitals of nine brazilian states: the influence of regional cultural factors. Clinics. 2008;63(1):51-8.

OBJECTIVE: Evaluating the interaction between mother or caregiver and infant through the Clinical Indicators of Risks in Infant Development and investigating whether local and cultural influences during infant development affect these clinical indicators. INTRODUCTION: The Clinical Indicators of Risks in Infant Development was created in order to fully assess infants' development and the subjective relationship between the babies and their caregivers. The absence of two or more Clinical Indicators of Risks in Infant Developments suggests a possibly inadequate mental development. Given the continental size of Brazil and its accentuated cultural differences, one might question how trustworthy these indicators can be when applied to each of the geographical regions of the country.

METHODS: This was a cross-sectional study with 737 infants from the capitals of 9 Brazilian states. The size of the initial sample population was based on a pilot study carried out in the cities of São Paulo and Brasília. The ages of children were grouped: 0-3 months, 4-7 months, 8-11 months and 12-18 months. The chi-square test was used together with analyses by the statistical software SPSS 13.0.

RESULTS: Statistical analysis of results from the different municipalities against the total sample did not reveal any statistically significant differences. Municipalities represented were Belém ( $\mathrm{p}=0.486)$, Brasília ( $\mathrm{p}=0.371)$, Porto Alegre $(\mathrm{p}=0.987)$, Fortaleza $(\mathrm{p}=0.259)$, Recife ( $\mathrm{p}=0.630)$, Salvador (0.370), São Paulo ( $\mathrm{p}=0.238)$, Curitiba $(\mathrm{p}=0.870)$, and Rio de Janeiro ( $\mathrm{p}=0.06)$.

DISCUSSION: Care for mental development should be considered a public health issue. Its evaluation and follow-up should be part of the already available mother-child assistance programs, which would then be considered to provide "full" care to children. CONCLUSIONS: Local habits and culture did not affect the results of the Clinical Indicators of Risks in Infant Development indicators. Clinical Indicators of Risks in Infant Development proved to be robust despite the specificities of each region.

KEYWORDS: Child. Subjectivity. Child Development. Mental Development. Clinical Indicators.

\section{INTRODUCTION}

The basis of mental health is established in the first years of life and depends on physical, affective and symbolic relationships established between an infant and his/ her mother or caregiver. These relationships promote the integration of human beings into their culture and build sub-

Faculdade de Medicina da Universidade de São Paulo - São Paulo/SP, Brazil. andre_decarvalho@yahoo.com.br

Received for publication on October 10, 2007.

Accepted for publication on November, 07, 2007. jectivity, which is the organizing axle of development in several different areas. Failures in the subjectivity building process lead to psychological disorders during child development ${ }^{1,2}$.

Until recently, it was believed that the diagnosis of severe psychological conditions could only be established after the child reached the age of 30 months ${ }^{3}$. However, other studies indicate that it is possible to detect them as early as 18 months or even earlier, at four months old ${ }^{4,5}$.

Evaluating scales of infant development are descriptive and classifying, seeking to measure only behaviors and neuropsychomotor indicators $6,7,8,9,10$. The main graduations 
used in Brazil to evaluate infant development are: the Gesell Development Schedules, known as the Gesell Scale 2, 5; the Denver Development Screening Test (DDST) ${ }^{11,12 \text {, }}$ 13; the Bayley Scales of Infant Development, known as Bayley's Test 7, 14; and the Escala de Desenvolvimento do Comportamento da Criança (EDC) ${ }^{8,15}$, or the Infant Behavior Development Scale, created by the Ministry of Health to standardize the services provided to children from zero to five years of age.

Only experts can use most of scales. The rubrics are also very long and too complex for basic public health care 9,16 . Besides, the variables involved in the constitution of subjectivity are neither evident nor important, being excluded or even neglected. Therefore, no user-friendly tool exists to identify the building of the infant's mental structure or allow us to relate the functions and the abilities on which they base their understanding of the world. The currently available tools simply point out behaviors that result in genetically programmed abilities and do not manage to evaluate mental development itself 9,16 .

In order to establish the indicators for analyzing an infant's mental development, it is necessary to clarify the concept of development that is being used as the reference. In general, pediatricians have relied solely on neuropsychomotor indicators. However, these indicators have proven to be only vaguely meaningful when it comes to specific mental difficulties that influence development. Besides, the practice of evaluating development based on neurological indicators does not comprise the process' perspective on which psychoanalysis is based: the principle that subjectivity is the main organizing aspect of development. ${ }^{17,18}$.

Subjectivity is, in turn, built as the child engages in language and culture ${ }^{12,19,20}$. Based on that perspective, it is possible to associate subjectivity with language, which marks and organizes the organic, anatomical, muscular and neurophysiological functions of the child, based on the connection that the child establishes with another human being, usually his/her mother or caregiver ${ }^{4}$.

It is possible to say that a baby is building his/her subjectivity upon manifestations that can be identified as responses that are exclusive and unique for that specific child when in contact with their mother, father or caregiver ${ }^{19}, 20$, ${ }^{21}$. In order for the baby to establish a satisfying circuit that involves the other person and allows development of self, the parents need to support certain functions by establishing a good and unique contact with their child ${ }^{21}$.

The onset of subjectivity can only be verified based on the indirect effects it determines ${ }^{20}$. The onset of subjectivity is supported by phenomenological signs that allow the assumption that subjectivity is present. These signs comprise the indicators, through which we will study how the mental development is related to an infant's development ${ }^{9}{ }^{19,20}$. These indicators should be clinically applicable, easy to read, operational and clinically transmittable.

Therefore, the Clinical Indicators of Risks for Infant Mental Development (CIRID) were created. They are based on primary activities that are part of the first months of in fant life, such as: sleeping, waking up, eating, seeing and having bowel movements ${ }^{4}$. These indicators are not only dependent on strictly organic factors, but also on symbolic signs determined by their caregivers; the first agents and transmitters of these signs are the parents. This is why the study of infant development should be entwined with the study of his mental constitution ${ }^{21,22}$.

The scores given by different indicators should be evaluated altogether. The absence of specific scores for the corresponding age group might point towards the existence of developmental issues ${ }^{9,20}$.

Another necessary factor to include when evaluating an infant's mental development is culture, which is markedly important. Different cultures may represent different conditions and lead to differently organized steps in the infant mental structure ${ }^{23}$. The cultural link is also important from a practical standpoint, because it suggests public health interventions. ${ }^{17,18,24-29}$

Because culture in all human communities can be reduced to a socially transmitted model in which feelings, thoughts and behavior prevail, its determining factors should be examined and evaluated so that the etiology and presentation of mental disorders are understood in detail ${ }^{12,22}$.

The objective of this study is to evaluate the subjectivity of the interaction between the mother (caregiver) and the infant through the Indicadores Clínicos de Risco de Desenvolvimento Infantil (CIRID - Clinical Indicators of Risks in Infant Development) and to investigate whether or not there are local influences on the building of this subjectivity during infant development ${ }^{12,19,20}$. These questions lead to another natural question: are there local differences in Brazil that directly affect the infant's process of identity building and development? Therefore, we shall verify whether habits and local cultures, as expressed by the infants' region or municipality, interfere in the evolution of CIRIDs.

\section{MATERIALS AND METHODS}

This study is part of an Interdisciplinary Research of Clinical Indicators for Early Detection of Risks of Infant Development, using data collected between January 2003 and March 2004. The sample population was chosen from public health services throughout nine Brazilian capitals São Paulo, Rio de Janeiro, Curitiba, Porto Alegre, Brasília, 
Recife, Salvador, Belém do Pará and Fortaleza - to ensure diverse geographical representation of urban centers around the country. The sample consisted of infants attended to by the pediatric clinic of the local public health care service. The ages of these children were grouped: 0-3 months; 4-7 months; 8-11 months and 12-18 months.

The size of the initial sample population was based on data collected in a pilot study carried out in São Paulo and Brasília and on the number of monthly appointments in each of the participating services. For all age groups, the data revealed a low prevalence (ranging from $0 \%$ to $34 \%$ ) of problems detected by the CIRIDs. Considering that this involved carrying out a non-representative number of appointments, we adopted $20 \%$ as the benchmark prevalence in calculating the sample. In order to define the total number of infants seen during a month, results from a previous survey were used; it had been conducted at some of the clinics involved, and its goal was to estimate the number of infants seen in each age group.

Table 1 shows the results of this survey in each clinic and provides estimates for the two clinics that had no available data. (This estimate was based on the average number of appointments in public health care services, except for Butantã.) The total number of monthly appointments was 3,492. However, for this study, 683 infants were required. The size of the sample was based on parameters such as the prevalence expected for the CIRID: $20 \%$ absolute precision, $3 \%$ (indicates how much the estimate should be off from the real rate) and a 5\% level of significance.

The Clinical Indicators of Risks in Infant Development was used as a tool by trained pediatricians to evaluate the infants. They observed the mother-infant and caregiver-infant relationship and recorded an indicator level of present, absent or not verified, along with the age group of the infant. Infants that missed two indicators in the CIRID were considered more likely to present mental and psychological deficiencies. The indicators are listed below (Table 2).
Seventy-eight percent of the infants in each age group were drafted from a list of entries in the Infant Health Care Program at the public health services. Each infant's indicators were examined during the follow-up appointments that took place during the first 18 months of life.

This cross-sectional study was conducted from June 2005 to May 2006 using the project database. Based on the initial appointments, a group of 737 infants were enrolled. Nevertheless, 76 of them were over 18 months of age and were excluded from the study, narrowing the sample population to 661 infants.

Data analysis entailed an epidemiological description of the infants to estimate the prevalence of the CIRIDs in each age group, city and region. The children were compared to groups of infants per age group, city or region, with two absent CIRIDs. SPSS 13.0 was the statistical software chosen for analysis; it was combined with the chisquare test to compare the significance among the different groups studied.

The blueprint of the project was approved by the Analysis of Research Projects Ethics Committee of Hospital das Clínicas da Faculdade de Medicina da Universidade de São Paulo. Parents or legal guardians, once educated about the study, signed informed consent forms.

\section{RESULTS}

The database of the project was submitted to a crosssectional analysis. Seven hundred and thirty-seven infants were selected based on the criteria established; 76 were excluded because they did not meet the requirements. Therefore, 661 infants were studied.

The epidemiological description of the database placed infants in each of the age groups (0-3 months; 4-7 months; 8-11 months and 12-18 months), within a municipality and region. There was a predominance of infants in São Paulo (37.5\%), Brasília (16.3\%) and Curitiba (9.1\%). When re-

Table 1 - Number of appointments per month distributed per health service and age group.

\begin{tabular}{|c|c|c|c|c|c|c|c|c|c|}
\hline \multirow[t]{2}{*}{ City } & \multirow{2}{*}{$\begin{array}{c}\text { Patients } \\
\text { per month }\end{array}$} & \multicolumn{2}{|c|}{$0-3$ months } & \multicolumn{2}{|c|}{$4-7$ months } & \multicolumn{2}{|c|}{$8-11$ months } & \multicolumn{2}{|c|}{12 - 18 months } \\
\hline & & $\mathrm{N}$ & $\%$ & $\mathrm{~N}$ & $\%$ & $\mathrm{~N}$ & $\%$ & $\mathrm{~N}$ & $\%$ \\
\hline Brasília & 200 & 104 & 52.0 & 39 & 19.5 & 22 & 11.0 & 34 & 17.0 \\
\hline Recife & 240 & 0 & & 0 & & 0 & & 0 & \\
\hline Rio de janeiro & 330 & 60 & 18.2 & 80 & 24.2 & 80 & 24.3 & 60 & 18.2 \\
\hline Porto Alegre (estimativa) & 234 & 0 & & 0 & & 0 & & 0 & \\
\hline Curitiba & 280 & 43 & 15.4 & 70 & 25.0 & 77 & 27.5 & 90 & 32.2 \\
\hline Belém & 205 & 60 & 15.4 & 40 & 25.0 & 85 & 27.5 & 20 & 32.2 \\
\hline Salvador (estimativa) & 234 & 0 & & 0 & & 0 & & 0 & \\
\hline São Paulo (Butantã/FMUSP) & 147 & 52 & 35.4 & 35 & 23.8 & 30 & 20.4 & 30 & 20.4 \\
\hline São Paulo (Paraisópolis) & 1.622 & 107 & 6.6 & 411 & 25.4 & 414 & 25.5 & 690 & 42.5 \\
\hline Total s/ (Re, Poá, Sa) & 2,784 & 426 & 15.3 & 675 & 24.2 & 708 & 25.4 & 924 & 33.2 \\
\hline Total & 3,492 & & & & & & & & \\
\hline
\end{tabular}


Table 2 - List of 31 Clinical Indicators of Risk for Child Development.

\begin{tabular}{|c|c|}
\hline Age group & Indicator \\
\hline $0-3$ months & $\begin{array}{l}\text { 1. When the child cries or screams, the mother knows what s/he wants. } \\
\text { 2. The mother speaks to the child in a style especially targeted at him/her (mummy language) } \\
\text { 3. The child reacts to the language used by her/his mother. } \\
\text { 4. The mother proposes something to the child and awaits for his/her reaction. } \\
\text { 5. Mother and child exchange looks. }\end{array}$ \\
\hline $4-7$ months & $\begin{array}{l}\text { 6. The child starts to distinguish day from night. } \\
\text { 7. The child uses different signals to express their different needs. } \\
\text { 8. The child asks for his/her mother and makes a pause to await for her answer. } \\
\text { 9. The mother talks to her child, directing some phrases to him/her. } \\
\text { 10. The child reacts (smiles, vocalizes) when the mother or somebody else is talking to her/him. } \\
\text { 11. The child actively looks for his/her mother's look. } \\
\text { 12. The mother supports the child's initiatives without sparing them from the effort } \\
\text { 13. The child asks somebody's else help without being passive. }\end{array}$ \\
\hline $8-11$ months & $\begin{array}{l}\text { 14. The mother realizes that some of the requests of the child can be just a way to get her attention. } \\
\text { 15. During personal care activities, the child actively tries to play with her/his mother. } \\
\text { 16. The child shows whether or not s/he likes something. } \\
\text { 17. Mother and child share a private language. } \\
\text { 18. The child does not recognize people s/he does not know. } \\
\text { 19. The child has his/her favorite objects. } \\
\text { 20. The child plays. } \\
\text { 21. The child looks for the approval on the eyes of an adult. } \\
\text { 22. The child accepts semi-solid, solid and diverse food. }\end{array}$ \\
\hline $12-18$ months & $\begin{array}{l}\text { 23. The mother alternates moments she dedicates to her child with her other interests. } \\
\text { 24. The child supports the brief absences of her/his mother well and reacts to long-lasting absences. } \\
\text { 25. The mother offers toys as alternates to get the child attention instead of her body. } \\
\text { 26. The mother no longer feels obliged to satisfy everything the baby asks for. } \\
\text { 27. The child curiously looks at everything that attracts his/her mother. } \\
\text { 28. The child likes to play with objects used by his/her mother and father. } \\
\text { 29. The mother starts to ask the infant to name what s/he wants, not accepting just his/her gestures. } \\
\text { 30. Parents set some behavior rules for the infant. } \\
\text { 31. The infant distinguishes objects that belong to his/her mother, father and to himself/herself. }\end{array}$ \\
\hline
\end{tabular}

gions were considered, the Southeast showed the highest (46\%), followed by the South $(18 \%)$ and the Center-West (16.3\%) (Figure 1).

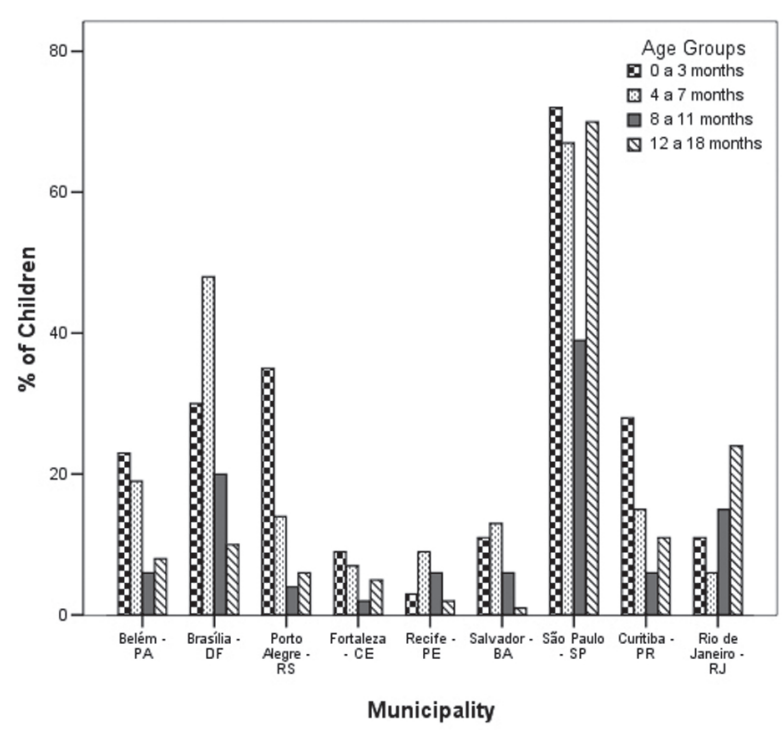

Figure 1 - Distribution of the total number of children that participate in this multicenter study according to their municipality
Then infant records were sorted according to their gender, the health service at which they were attended, the number of appointments and the age group, regardless of where they lived. The percentage of boys $(52.93 \%)$ was slightly higher than that of girls $(47.07 \%)$ and at the time of the study, most infants were between 12-18 months (74.54\%) (Figures 2 and 3).

The absence of two or more CIRIDs suggested a possibly inadequate mental development. The percentage of infants with this prognosis were sorted according to age group, municipality or region and shown in table 3: 11 out of 222 infants 0-3 months old, 26 out of 172 infants 4-7 months old, 20 out of 84 infants 8-11 months old, and 31 out of 106 infants 12-18 months old.

\section{$47,07 \%$}
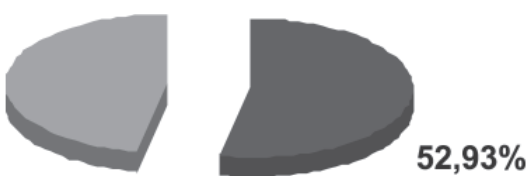

Boys

Girls

Figure 2 - Distribution of the total number of children that participate in this multicenter study according to their gender. 
Table 3 - Children who did not present 2 or more IRDI distributed according to different age groups (0-3 months; $4-7$ months; $8-11$ months and $12-18$ months) and municipality.

\begin{tabular}{lcccc}
\hline CITY & \multicolumn{2}{c}{ percentage of children who did not present 2 or more IRDIs according to the municipality and age group } \\
& $0-3$ months & $4-7$ months & $8-11$ months & $12-18$ months \\
\hline & Yes & Yes & Yes & $0 \%$ \\
Belém & $9.1 \%$ & $7.7 \%$ & $20 \%$ & $3.5 \%$ \\
Brasília & $18.2 \%$ & $26.9 \%$ & $5 \%$ & $9.7 \%$ \\
Porto Alegre & $9.1 \%$ & $11.5 \%$ & $0 \%$ & $0 \%$ \\
Fortaleza & $9.1 \%$ & $0 \%$ & $0 \%$ & $6.5 \%$ \\
Recife & $9.1 \%$ & $7.7 \%$ & $0 \%$ & $0 \%$ \\
Salvador & $0 \%$ & $0 \%$ & $50 \%$ & $51.6 \%$ \\
São Paulo & $18.2 \%$ & $38.5 \%$ & $0 \%$ & $0 \%$ \\
Curitiba & $27.3 \%$ & $0 \%$ & $25 \%$ & $22.6 \%$ \\
Rio de Janeiro & $0 \%$ & $7.7 \%$ & & $0.6 \%$ \\
\hline
\end{tabular}

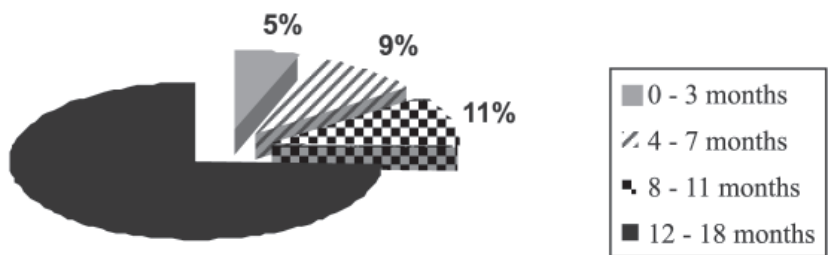

$75 \%$

Figure 3 - Distribution of the total number of children participating in this multicenter study according to their age group.

These infants were from Recife (25\%), Rio de Janeiro (25\%), São Paulo (15.3\%), Porto Alegre (13.5\%) and Brasília (12.9\%). Each municipality was compared to all the other cities combined, and each region was compared to all the other regions combined. Infants were sorted ac- cording to their age groups when the municipalities were compared.

There was no statistically significant difference between the municipalities (Table 4), a tendency that repeated itself when the municipalities were sorted by regions (Table 5). Similarly, there was no statistically significant difference when the sample was sorted by age group and each municipality was compared with all municipalities combined.

\section{DISCUSSION}

Care for mental development should be considered an issue of public health, and its evaluation and follow-up

Table 4 - Each municipality was compared to all the others combined. P value obtained did not show any significant difference in the municipalities.

\begin{tabular}{|c|c|c|c|c|}
\hline \multirow[t]{2}{*}{ CITIES } & \multicolumn{2}{|c|}{ Children that did not present 2 or more IRDIs } & \multirow[t]{2}{*}{ Total } & \multirow[t]{2}{*}{ Chi-square ( $\mathrm{p}$ value) } \\
\hline & NO & YES & & \\
\hline Belém & $51(91.1 \%)$ & $5(8.9 \%)$ & $56(100 \%)$ & $\mathrm{p}=0.486$ \\
\hline Brasília & $98(87.1 \%)$ & $10(12.9 \%)$ & $108(100 \%)$ & $\mathrm{p}=0.371$ \\
\hline Porto Alegre & $52(86.5 \%)$ & $7(13.5 \%)$ & $59(100 \%)$ & $\mathrm{p}=0.987$ \\
\hline Fortaleza & $22(95.7 \%)$ & $1(4.3 \%)$ & $23(100 \%)$ & $\mathrm{p}=0.259$ \\
\hline Recife & $15(75 \%)$ & $5(25 \%)$ & $20(100 \%)$ & $\mathrm{p}=0.63$ \\
\hline Salvador & $31(100 \%)$ & $0(0 \%)$ & $31(100 \%)$ & $\mathrm{p}=0.37$ \\
\hline São Paulo & $214(84.7 \%)$ & $34(15.3 \%)$ & $248(100 \%)$ & $\mathrm{p}=0.238$ \\
\hline Curitiba & $57(95 \%)$ & $3(5 \%)$ & $60(100 \%)$ & $\mathrm{p}=0.87$ \\
\hline Rio de Janeiro & $43(75 \%)$ & $13(25 \%)$ & $56(100 \%)$ & $\mathrm{p}=0.06$ \\
\hline
\end{tabular}

Table 5 - Each region was compared with the entire sample. P value was obtained.

\begin{tabular}{|c|c|c|c|c|}
\hline \multirow[t]{2}{*}{ Regions } & \multicolumn{2}{|c|}{ Children that did not present 2 or more IRDIs } & \multirow[t]{2}{*}{ Total } & \multirow{2}{*}{$\begin{array}{c}\text { Chi-Square } \\
\text { (p value) }\end{array}$} \\
\hline & No & Yes & & \\
\hline North & $51(91.1 \%)$ & $5(8.9 \%)$ & $56(100 \%)$ & $\mathrm{p}=0.12$ \\
\hline Northeast & $68(91.9 \%)$ & $6(8.1 \%)$ & $74(100 \%)$ & \\
\hline South & $109(91.6 \%)$ & $10(8.4 \%)$ & $119(100 \%)$ & \\
\hline Southeast & $257(84.5 \%)$ & $47(15.5 \%)$ & $304(100 \%)$ & \\
\hline Center-West & $98(90.7 \%)$ & $10(9.3 \%)$ & $108(100 \%)$ & \\
\hline Total & $583(86.7 \%)$ & $78(13.3 \%)$ & $661(100 \%)$ & \\
\hline
\end{tabular}


should be part of the already available mother-child assistance programs, which would then be considered as providing "full" care to children's health.

At the beginning of the 1980's, when the Ministry of Health proposed to develop the standards of care for children between zero and five years of age, which included follow-up of growth and development, it was necessary to develop a simplified form for monitoring development. The forms used by specialists or pediatricians were too long and complex for the basic health services ${ }^{8}$.

The development of clinical indicators for early detection of mental disorders aiming at prevention, as well as the improvement of pediatricians and other health professionals involved in basic care, is the objective of the interdisciplinary project upon which this study was developed.

Brazil is a true 'melting pot' in which several ethnic groups have left their cultural imprint. Considering that culture can be defined as "knowledge, values, perceptions and practices shared by members of a certain society and passed on from one generation to the next," and emphasizing that its components are "intertwined and inter-related in order to build an unity that rules the functioning of that specific society," then from an operational standpoint, culture is a set of extremely heterogeneous elements, including language, ethnic groups, religions, traditions, beliefs, values, interpersonal relationships, production models and social organization, among others ${ }^{30,31,32}$. Thus, it is disputable whether the Clinical Indicators of Risk for Early Detection of Child Mental Disorders (CIRIDs) can be applied in different regions and cities of the country without the interference by local culture. It is known, for instance, that the northeast is compromised by a low variety of food, limited and cyclic production, precarious - or lacking - water resources, unemployment and weak public educational and health systems that lack material support. ${ }^{33}$ The southeast, on the other hand, faces different difficulties, as it is the country's most developed region.

At first, it might be considered that the CIRIDs should be adapted to local conditions so that the results are not affected by culture. Studies have shown incompatible results when geographic regions, ethnic groups or social classes are considered in aggregates, especially when subjective experiences are involved, as they present an obstacle to verbal communication and might also affect writing, such as questionnaires' answering, scoring and psychological tests ${ }^{34,35}$.

Brazil claims only one language, but local idioms and accents are vast. In addition, the impact of culture on the process of looking for professional help must be considered. In some countries, people from different socio-demographic groups adopt specific ways to communicate and understand problems related to general or mental health. These are not always noticed by Pediatrics Clinics or taken into consideration by research tools. As for the process of looking for professional help, research has emphasized how the concept of health and disease of an individual is affected by culture and how this guides the process of looking for help ${ }^{36}$.

This study examined the CIRIDs, applying statistics to each region and each municipality that took part in this project. No statistically significant differences were found. Therefore, this study confirmed that results produced by applying the indicators will be valid throughout the country. It proves that, despite Brazil's different cultural manifestations, a single method can be used to evaluate mental development over the whole territory.

Some studies suggest that when the evaluation tool is developed in the culture in which it is going to be used, no translation or adaptation processes are required; this is thought to promote cultural equivalence. Thus, to avoid this adaptation, several linguistic and sociocultural factors must be considered when determining transcultural equivalence. Studies recommend that this equivalence be evaluated in five dimensions: (1) semantic (same meaning); (2) content (relevant items); (3) technical (data collection); (4) criterion (same standard interpretation); and (5) concept (same theoretical construct) ${ }^{37,38}$. In Brazil, indicators are perfectly adapted to the local cultural conditions.

It is not recommended that a tool used for clinical evaluation be created in one country and then applied in another. Reinforcing the need for a national tool to evaluate the mental development of children, some studies report that there are relevant sociocultural differences between the populations of countries in which the tools are developed and the vast majority of the foreign population in which they are applied. Based on that, when examining the CIRIDs, we are, in effect, testing the use of standardized diagnostic tools developed in Brazil. As such, the production, interpretation and comparability of data match our reality ${ }^{39}$.

Therefore, to evaluate child development by incorporating subjectivity (examined through CIRIDs) into the investigation of regional cultural influences in the development of this subjectivity, we also address the question of local and cultural differences in Brazil that directly affect children in their identity-building and developmental processes. Results indicate that the customs and regional cultures expressed by each region or municipality do not affect the clinical indicators of the mental development of children.

Thus, it is expected that, based on this study, these indicators will be converted into a tool for diagnostic-epide- 
miological purposes. Above all, this tool is therapeutic, being associated with a plan for preventing disorders in childhood. We also intend to develop a method to train pediatricians as agents to prevent and detect the early signs of risk for abnormal child development.

The objective of this study was to evaluate the subjectivity of the mother- or caregiver-infant interaction through Clinical Indicators of Risks in Infant Development and to investigate whether there are local influences in the building of this subjectivity during infant development $12,19,20$.
Results show that habits do not affect the progress of clinical indicators in infants' mental development.

Additionally, the use of the CIRID in Brazil proved to be adapted to local conditions. Finally, we have started a study to meet the need for a national tool to evaluate children's mental development. We have tested the use of standardized diagnostic tools developed in our country (the CIRID) so that the production, interpretation and comparability of these data are suitable to our country.

\section{REFERENCES}

1. Freud S. (1918-1973). "Historia de una neurosis infantil:Caso del Hombre de los lobos". In: Obras Completas. Madrid:Biblioteca Nueva, v.2.;p.1941-2010.

2. Gesel A. A Criança de 0 a 5 Anos. $4^{\mathrm{a}}$ ed. São Paulo:Martins Fontes; 1996.

3. Crossley SA. "Síndrome de Down e autismo?" In:BUSNEL, M.C. (Org.) A Linguagem dos Bebês:Sabemos Escutá-los? São Paulo: Escuta;1997.

4. Baron-Cohen. Can autism be detected at 18 months? The needle, the haystack, and the CHAT. Br J Psychiatr. 1992;161:839-43.

5. Gesell A, Amatruda C. Diagnostico del desarrollo normal y anormal del niño:metodos clinicos y aplicaciones practicas. Buenos Aires: Medico Quirúrgica, 1945.

6. Bastista Pinto E, Vilanova LCP, Vieira RM. O Desenvolvimento do Comportamento da Criança no primeiro ano de vida:padronização de uma escala para a avaliação e o acompanhamento. São Paulo: FAPESP/ Casa do Psicólogo, 1997.

7. Bayley N. Bayley scales of infant development. New York: Psychological Corporation;1969.

8. Brasil. Ministério da saúde. Secretaria de programas especiais. Divisão nacional de saúde materno-infantil. Acompanhamento do Crescimento e Desenvolvimento - Normas Técnicas. Brasília:DINSAMI;1984.

9. Honzik MP. "Value and limitations of infant tests". In: LEWIS, M. Origins of intelligence:infancy and early childhood. New York: Plenum, 1977. p. $59-95$.

10. Zero to three. Diagnostic Classification:0-3. Washington:National Center for Infants, Toddlers and Families, 1994.

11. Frankenburg Doods JB. The Denver Developmental Screening Test. Pediatrics. 1967;71:181-91

12. Hallowell AI. Culture and mental disorder. J Abnorm Soc Psychol. 1934;29:1-9.

13. Batista Pinto E. Os sintomas psicofuncionais e as consultas terapêuticas pais/bebê. Estudos de psicologia. [no prelo]

14. Bayley, N. Bayley scales of infant development $-2^{\text {nd }}$ edition. New York: Psychological Corporation, 1993.
15. Vieira RM. O que é isto - o comportamento? Boletim de Psiquiatria. 1974;7:115-44.

16. Giel, R. et al. Childhood mental disorders in primary health care:results of observations in four developing countries. A report from the who collaborative study on strategies for extending mental health. Pediatric. 1981;68:677-83

17. Devries MW. "Kids in context:temperament in cross-cultural perspective". In: Carey WB, McDevit SC (eds). Prevention and early intervention:individual differences as risk factors for the mental health of children. A Festschrift for Stella Chess and Alexander Thomas. New York:Brunner/Mazel Publishers. 1994; p. 126-39.

18. Devries MW. Babies, brains and culture:optimizing neurodevelopment on the savanna. Acta Paediatr. 1999;88:43-8.

19. Trevarthen C. "Communication and cooperation in early infancy. A description of primary intersubjectivity". In: Bullowa M. (Ed.) Before speech:The beginning of human communication. London:Cambridge University Press. 1979;321-347.

20. Trevarthen C, Aitken KJ. Infant intersubjectivity: research, theory, and clinical applications. J Child Psychol Psychiatry. 2001;42:3-48

21. Chemama R. Dicionário de Psicanálise Larousse. Porto Alegre:Artes Médicas, 1995.

22. Coll CG, Akerman A, Cicchetti, D. Cultural influences on developmental processes and outcomes:implications for the study of development and psychopathology. Dev Psychopathol. 2000;12:333-56.

23. Rothbaum F et al. The development of close relationships in Japan and the United States: Paths of symbiotic harmony and generative tension. Child Development. 2000;71:1121-42.

24. Fleitlich BW, Goodman R. Social factors associated with child mental health problems in Brazil: cross sectional survey. BMJ. 2001;323:599600

25. Fleitlich B. The prevalence of psychiatric disorders in 7-14 year olds in the South East of Brazil. London. (Dissertation) - Department of Child and Adolescent Psychiatry Institute of Psychiatry Kings College London, University of London, 2002

26. Bonaiuto M, Bonnes M. Multiplace analysis of the urban environment:a comparison between a large and small Italian city. Environ Behav. 1986:28:699-747. 
27. Spencer C, Wooley H. Children and the city: a summary of recent environmental psychology research. Child Care Health Dev. 2000;26:181-97.

28. Kilbride JE, Kilbride PL. Sitting and smiling behavior of Baganda infants: the influence of culturally constituted experience. J CrossCultural Psychol. 1975;6:88-107.

29. LeVine R. Parental goals:a cross-cultural view. Teachers College Record. 1974;76:226-39.

30. Alarcon RD. Culture and Psychiatric Diagnosis: Impact on DSM-IV and ICD-10. Psychiatr Clin North Am. 1995;18:449-65.

31. Leighton AH. Culture and Psychiatry. Can J Psychiatr. 1981;26:522-29.

32. Vaifas R, Venância RP, Kodama K, Grinberg K. Brasil: 500 anos de povoamento. IBGE. Rio de Janeiro - RJ. Centro de Documentação. 240p. Ilustrado cores. 30 x $32 \mathrm{~cm} ; 2000$.

33. Silva FS, Azevedo MRC. Children from the backlands: life styles. An ethnographic study on families from Santa Cruz do Banabuiú - State of Ceará. Rev Bras Crescimento Desenvolv Hum. 2001;11:17-34.
34. Brislin R. "The Wording and Translation of Research Instruments". In: Lonner JW, Berry JW (eds.) Field Methods in Cross-Cultural Research. Beverly Hills: Sage; 1986.

35. Scheff TS. Is Accurate Cross-cultural Translation Possible? Current Anthropology. 28:365.

36. Angel R, Thoits P. The Impact of Culture on the Cognitive Structure of Illness. Culture, Med Psychiatr. 1987;11:465-94.

37. Flaherty JA. "Appropriate and Inappropriate Research Methodologies for Hispanic Mental Health". In:GAVIRIA, M. (ed.) Health and Behavior:Research Agenda for Hispanics. Chicago:University of Illinois Press. 1987.

38. Flaherty JA et al. Developing Instruments for Cross-cultural Psychiatry Research. J Nerv Ment Dis. 1988;176:257-63.

39. Jorge MR. Transcultural adaptation of psychiatric instruments in mental health. Rev Psiquiatr Clin. 1998;25:233-9. 